\title{
Plant Knowledge of the Shuhi in the Hengduan Mountains, Southwest China ${ }^{1}$
}

\author{
Caroline S. Weckerle, Franz K. Huber, Yang YongPing, \\ AND SUN WEIBANG
}

\begin{abstract}
Weckerle, Caroline S. (Kunming Institute of Botany, Chinese Academy of Sciences, Heilongtan, Kunming 650204, China, and Institute of Systematic Botany, University of Zurich, Zollikerstrasse 107, 8008 Zurich, Switzerland; Tel: 008687152122 74; email: weckerle@ ethnobot.ch, weckerle@systbot.unizh.ch), Franz K. Huber, Yang Yongping, and Sun Weibang (Kunming Institute of Botany, Chinese Academy of Sciences, Heilongtan, Kunming 650204,China; e-mail: huber@ethnobot.ch, yangyp@mail.kib.ac.cn,wbsun@mail.kib.ac. cn). Plant Knowledge of THe Shuhi in The Hengduan Mountains, Southwest CHINA. Economic Botany 60(1):3-23, 2006. The Shuhi are a Tibeto-Burman ethnic group of around 1,500 people living exclusively in the Shuiluo Valley, southwest China. We documented their plant knowledge concerning wild collected species, and analyzed food, medicine, and ritual uses. Overall, uses, collection sites, and use frequencies of 136 plant species were documented. The plants were divided in fodder (46 spp.), food (43 spp.), medicine (27 spp.), ritual plants (20 spp.), fuelwood (17 spp.), plants used for construction (8 spp.), ornamentals (2 spp.), and "others" (34 spp.). Food plants mainly consist of fruits and leafy vegetables, and the uses are comparable with those of other ethnic groups in the area. Knowledge about medicinal plants is relatively limited, since traditional Shuhi healers use ritual and other healing methods instead of medicinal plants. Ritual plants play an important role relative to human well-being. Villagers and ritualists use them to keep the environment clean of malevolent spirits and to maintain a good relationship with the deities. All habitats, from the dry shrub vegetation at the valley bottom up to the alpine shrub, are used for plant collection, but $87 \%$ of all species are collected in the near vicinity of the villages around the fields and in the dry shrub vegetation. Finally, we postulate two main factors influencing wild plant use among the Shuhi: cultural values and accessibility.
\end{abstract}

Key Words: Ethnobotany, food plants, medicinal plants, ritual plants, Shuiluo Valley, TibetoBurman.

The Hengduan Mountains region is well known for its biological diversity and its cultural richness. It is situated at the Himalayan foothills of southwest China, spanning southwest Sichuan, northwest Yunnan, and part of eastern Tibet. Mountains reach altitudes of 7,500 $\mathrm{m}$ while networks of streams and rivers, including the Mekong, Salween, and Yangtze, dissect innumerable valleys. The region is one of the world's 25 biodiversity hotspots as identified by Conservation International (Myers et al. 2000; Olson and Dinerstein 2002). It is one of the richest temperate floristic areas in the world, harboring 3,500 endemic species with

\footnotetext{
${ }^{1}$ Received 16 October 2005; accepted 12 November 2005 .
}

high medicinal plant diversity (Wang et al. 1995; Morell 2002). The Hengduan Mountains region belongs to the eastern part of "Ethnic Tibet" (Baumer and Weber 2002:17-18). For several thousands of years, the area has been inhabited by a large number of ethnic groups with distinct and different languages, customs, and land management practices (e.g., Hsu 1998).

Current ethnobotanical studies in the SinoHimalayan area (including northern Nepal and India) concentrate on nontimber forest products, mainly medicinal plants and their local uses and exploitation, as well as the resulting impacts on the environment (see Kala 2000; Saxena et al. 2001; Ghimire, McKey, and Aumeeruddy-Thomas 2005). There are few English articles dealing with current ethnobotanical research in the Hengduan Mountains. Most 


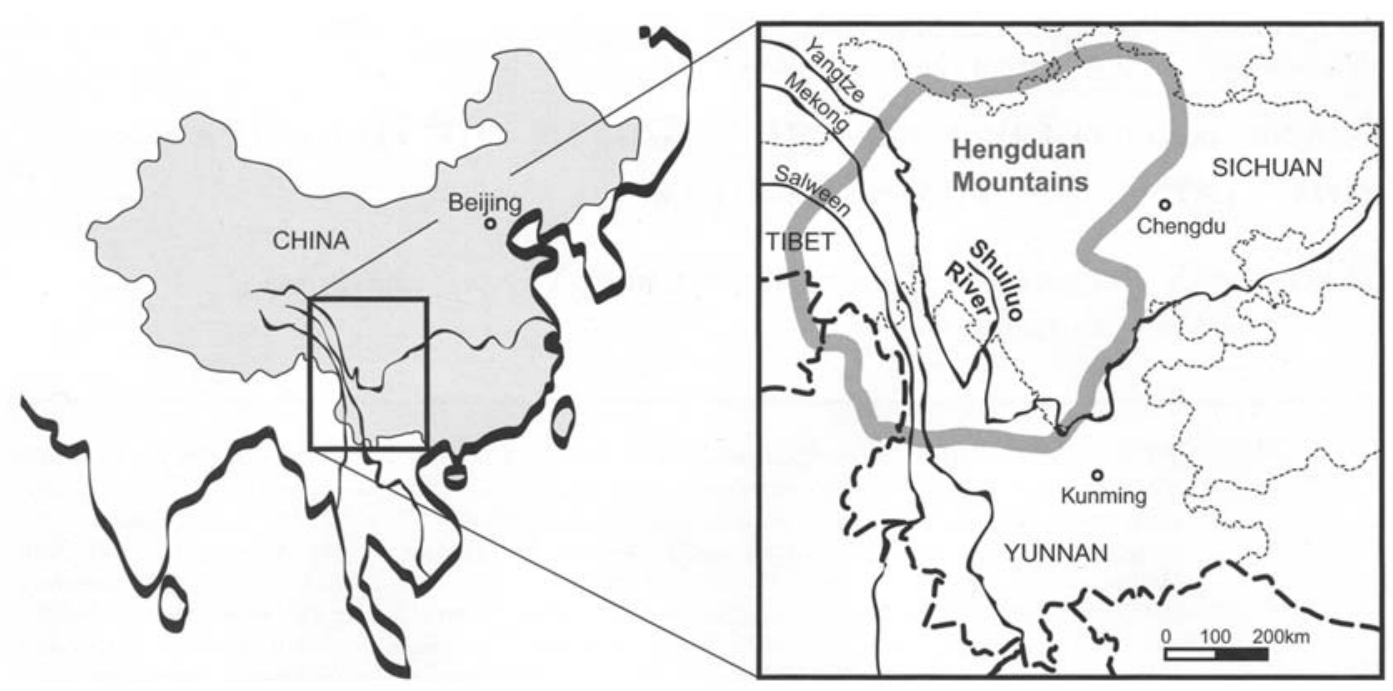

Fig. 1. Location of the study area in southwest China.

research has been conducted in NW Yunnan (see Pei, Li, and Yin 1996; Long et al. 2003; Huang, Pei, and Long 2004; Salick et al. 2004). Pei, Li, and Yin (1996) and Huang, Pei, and Long (2004) document medicinal plant uses. The former study concentrates on local markets, whereas the latter documents local uses among the Lisu people. Long et al. (2003) stress the various uses of the lacquer tree (Toxicodendron vernicifluum [Stokes] F.A.Barkley) in agroforestry systems, while Salick et al. (2004) investigate the correlation between useful plants and biodiversity along elevation gradients.

The present study has been conducted in a Shuhi community, a little-known ethnic group living exclusively in the remote Shuiluo valley, situated in the south of the Hengduan Mountains, southwest Sichuan. Only recently, in 2000 , has the valley been made accessible by road. As a consequence, acculturation pressures are increasing, and the lives of its inhabitants are rapidly changing. Other than a linguistic study (Sun 1990) and two articles about traditional utilization of Juglans regia $\mathrm{L}$. and Hordeum vulgare L. (Weckerle et al. 2005a, $2005 \mathrm{~b}$ ), no ethnological or ethnobotanical research articles have been published on the Shuhi. Since acculturation processes are often accompanied by a loss of indigenous plant knowledge (e.g., Benz et al. 2000), ethnobotan- ical studies are urgently needed to document the present knowledge and to provide a baseline for future analysis regarding knowledge and use changes. This study aims to document the traditional knowledge of the Shuhi concerning wild collected plant species, and to analyze food, medicinal, and ritual plant uses.

Wild collected species as defined here are plants which are not cultivated, i.e., which are not deliberately planted and managed by humans. The term does include semicultivated plants, which are protected to some degree, e.g., not consciously destroyed in agricultural activities or fuelwood collection (see Berlin 1992:120).

\section{Study Area}

\section{GeOgraphical Aspects and Vegetation}

The Shuiluo Valley in the Sichuan Province is situated in the south of the Hengduan Mountains, ca. $28^{\circ} \mathrm{N}$ and $101^{\circ} \mathrm{E}$, at an elevation of $2,000-6,000 \mathrm{~m}$. The Shuiluo River, a tributary to the Yangtze River, is approximately $150 \mathrm{~km}$ long (Fig. 1). Southwest monsoon from the Indian Ocean strongly influences the climate, resulting in a rainy season from June to October and allowing tropical vegetation to reach almost $29^{\circ}$ north latitude (Wang et al. 1995). The annual rainfall in the Shuiluo valley ranges from 400 to $1,000 \mathrm{~mm}$ (unpublished data, Wang 
1961). The vegetation types can be divided into a dry to semidry valley bottom characterized by shrub vegetation $(2,000-2,400 \mathrm{~m})$, subtropical mixed pine and oak forests $(2,400-3,500 \mathrm{~m})$, temperate and cold-temperate mixed conifer forests $(3,500-4,400 \mathrm{~m})$, and alpine vegetation (above 4,400 m; Handel-Mazzetti 1921).

\section{ETHNOGRAPHIC BACKGROUND}

The Shuiluo Valley is inhabited by five different Tibeto-Burman ethnic groups living close together but separated by their languages: the Gami-Tibetans, Pumi, Shuhi, Moso, and Naxi. The first three, summarized officially as Tibetans (Chinese: zangzu), are in the majority with about 4,500 inhabitants. Around 1,500 of them are Shuhi people, living exclusively in the Shuiluo valley. The Naxi comprise about 400 and the Moso about 300 inhabitants (Ma Shuji 1996, personal communication). The kinship of the Shuhi to other ethnic groups is unclear, but is the subject of recent ethnological studies in the area (Weng 2005, personal communication).

The ethnic groups usually live in confined settlements with 20-30 scattered buildings or, more rarely, in hamlets with more closely arranged houses. All ethnic groups rely on subsistence agriculture with crop rotations and two harvests per year. Both the Shuhi and the Moso are paddy farmers and are settled near the valley bottom between $2,000-2,400 \mathrm{~m}$. The other groups cultivate mainly wheat, barley, and corn, and tend to live at higher elevations, especially the Gami and Pumi.

The religion is influenced by both Tibetan Buddhism (Lamaism) and animistic Bon religion (Baumer 1999). The Shuhi rely on shamans, so-called dumbu priests, as well as lamaistic priests. The dumbus are the traditional healers of the Shuhi. Their concept of health and disease is related to various kinds of spirits, which are thought to be responsible for human illness.

\section{Research Methods}

Fieldwork was conducted for a total of eight months in 1996, 2004, and 2005. It consisted of interview surveys, extensive participant observation, and the collection of plant voucher specimens. A total of 50 households were visited in five Shuhi villages. In Lanman village, repeated interviews were conducted in all houses (17) of one hamlet. We attempted to conduct interviews with one-third to one-half of randomly selected households in the other villages and hamlets: Xiwa (9), Dongla (6), Pingweng (11), and Mianbang (7). Data were collected through semistructured interviews with both male (34) and female (29) informants, including extended open-ended interviews with the village leaders and persons chosen based on recommendations of villagers. Interviews were carried out in Chinese or the local language with the assistance of translators. Usually one or two "main" interviewees were questioned, although often other people were around and participated in the discussions. The "main" interviewees were 20-70 years old, with an average age of 43 .

The semistructured interviews covered the socioeconomic situation (family background, age, income, education, etc.) as well as knowledge of traditional plant use, health care, and healing practices, traditional and recent. Since it was generally difficult to get extensive information on plant use during the interviews, walks in the area (through fields and shrub vegetation) with key informants were conducted, which often triggered their recognition of useful plants. In Lanman village, extensive work with two key informants also included the discussion of randomly collected plants. All information received from key informants was cross-checked with at least two additional informants.

Besides interviews we also collected plant use information (including local names) by informal conversation with people encountered in the fields. Participant observation revealed information on the cultural context of plant use as well as the use frequency of wild collected plant species. Based on these observations and discussions with key informants in different villages, a ranking of use frequencies was developed. Five different categories ranging from daily use (i.e., 5-7 days per week) to very rarely (i.e., less than two times per year; cf. Fig. 2) were chosen and applied to all plants for their main production season, when the plant part used is available. Toona sinensis leaves and Pteridium revolutum shoots, for example, can only be collected during springtime, but are then frequently consumed. Other plants, however, are used during the whole year with constant frequency, such as Pinus yunnanensis, Pistacia weinmannifolia, or Cupressus funebris. Although this might have a different impact on 


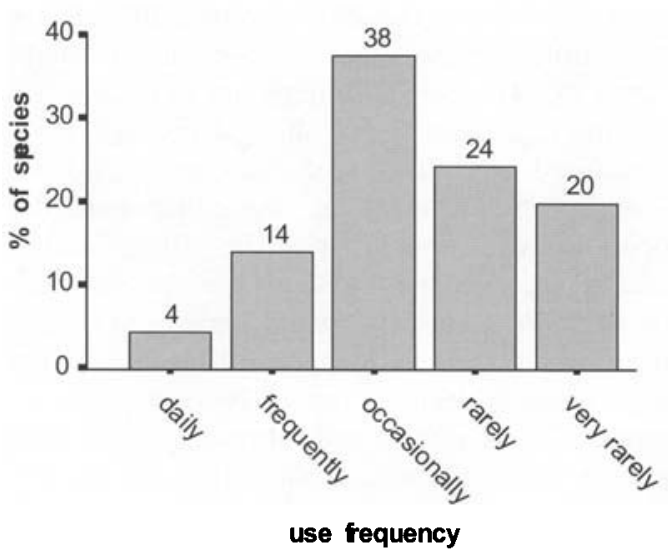

Fig. 2. Use frequency of wild collected species: daily, 5-7 days per week; frequently, 1-4 days per week; occasionally, 1-3 times per month; rarely, less than 12 times per year; very rarely, less than two times per year. Calculated for the main production season of the plant.

the collected species and their population, it is not considered here.

As shown in Fig. 3, the collection sites of the species have been divided into seven different vegetation zones and habitats: a, fields $(2,100-$ $2,400 \mathrm{~m}) ; \mathrm{b}$, dry shrub vegetation $(2,000-2,400$ $\mathrm{m})$; c, irrigation channels and streams $(2,000$ $2,400 \mathrm{~m}) ; \mathrm{d}$, Pinus yunnanensis forest $(2400$ $2800 \mathrm{~m})$; e, pine mixed forest $(2,800-3,500 \mathrm{~m})$; $\mathrm{f}$, conifer mixed forest $(3,500-4,400 \mathrm{~m})$; and $\mathrm{g}$, alpine shrub (above 4,000-4,500 m).

Local plant names and key features of the interviews were recorded on tape and are deposited at the first author's home. The plant specimens were identified at the herbarium of the Kunming Institute of Botany (KUN), where they are also deposited. Nomenclature follows the Flora of China (1994 to present), the Hengduan Mountain Vascular Plants (Wang et al. 1994), and The International Plant Names Index (2004).

The research was performed according to the biodiversity rights of China, and the results are published with the agreement of local village leaders.

\section{Results AND Discussion}

\section{Plant Use Categories, Use Frequency, AND COLlECTION Sites}

A total of 136 wild collected plant species were recorded (Appendix 1). The documented

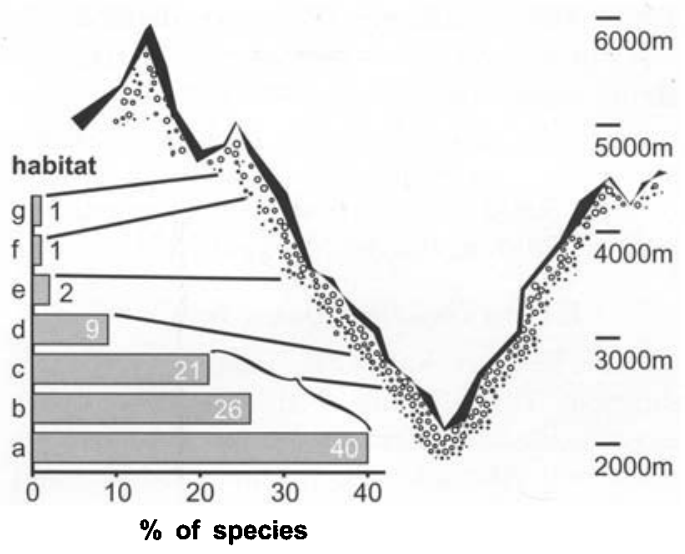

Fig. 3. Collection sites of the plants. The black lines indicate the upper limit of the vegetation zones and habitats where the plants are collected: a, fields $(2,100-2,400 \mathrm{~m}) ; \mathrm{b}$, dry shrub vegetation $(2,000-$ $2,400 \mathrm{~m}) ; \mathrm{c}$, irrigation channels and streams $(2,000$ $2,400 \mathrm{~m})$; d, Pinus yunnanensis forest $(2,400-2,800$ $\mathrm{m})$; e, pine mixed forest $(2,800-3,500 \mathrm{~m})$; $\mathrm{f}$, conifer mixed forest $(3,500-4,400 \mathrm{~m})$; $\mathrm{g}$, alpine shrub (above $4,000-4,500 \mathrm{~m})$.

plant uses were divided into seven main categories ordered according to the number of species they comprise: fodder plants (46 spp.), culinary or food plants (43 spp.), medicinal plants (27 spp.), ritual plants (20 spp.), fuelwood (17 spp.), plants used for construction (8 spp.), and ornamentals ( $2 \mathrm{spp}$.). The eighth category of "others" (34 spp.) includes various plant uses such as fertilizer, as broom, or to make fences and cords, which will not be dealt with in this paper. While the first seven categories coincide with emic use categories found in grouping analysis (unpublished data), the category "others" combines several emic categories, e.g., "fertilizer" and "cleaning."

Figure 2 shows that only $18 \%$ of the wild collected species are used on a daily or frequent basis, while the majority of the species are used occasionally or rarely. However, other than the medicinal plants, species with frequent use are found in every use category (Table 1). Wild collected species used on a daily basis belong to the categories "ritual plants" and "fuelwood."

Of the used plant species, $87 \%$ are collected in the near vicinity of the village, i.e., in the fields, the shrub vegetation, and along the channels and streams (Fig. 3). Similar trends have been observed in other ethnobotanical 
Table 1. Cross tabulation of use Categories and USE FReQuency.

\begin{tabular}{|c|c|c|c|c|c|c|c|c|c|}
\hline & \multicolumn{8}{|c|}{ Use Categories* (Number of Species) } & \multirow[b]{2}{*}{ Total } \\
\hline & CUL & MED & RIT & FOD & FUEL & CON & ORN & ОтН & \\
\hline \multicolumn{10}{|l|}{ Use Frequency } \\
\hline Daily (5-7 days per week) & $\mathbf{0}$ & 0 & 3 & 0 & 1 & 0 & 0 & 2 & 6 \\
\hline Frequently (1-4 days per week) & 11 & 0 & 3 & 1 & 2 & 1 & 1 & 3 & 22 \\
\hline $\begin{array}{l}\text { Occasionally ( } 1-3 \text { times } \\
\text { per month) }\end{array}$ & 15 & 0 & 10 & 25 & 9 & 0 & 1 & 7 & 67 \\
\hline $\begin{array}{l}\text { Rarely (less than } 12 \text { times } \\
\text { per year) }\end{array}$ & 10 & 5 & 3 & 19 & 5 & 4 & 0 & 13 & 59 \\
\hline $\begin{array}{l}\text { Very rarely (less than two times } \\
\text { per year) }\end{array}$ & 7 & 22 & 1 & 1 & 0 & 3 & 0 & 9 & 43 \\
\hline Total & 43 & 27 & 20 & 46 & 17 & 8 & 2 & 34 & \\
\hline
\end{tabular}

* CUL, culinary or food plants; MED, medicinal plants; RIT, ritual plants; FOD, fodder; FUEL, fuelwood; CON, construction wood; ORN, ornamentals; OTH, other uses. A single species can appear in more than one use category.

studies. For example, Salick et al. (1999) stress that the Dusun people of Mt. Kinabalu, Borneo, collect most of the useful plants close to their settlements, and only a few plants are collected from higher elevations. It is unclear whether this behavior is due to convenience or the experience that habitats close to human settlements contain more useful plants. Recent quantitative studies confirm the positive correlation between overall species richness and the number of useful plant species (Salick et al. $1999,2004)$. Both the dry shrub vegetation and the vegetation between and around the fields are known for high species diversity, which exceeds the diversity of the forests at higher altitudes (Salick et al. 1999, 2004). Thus it might be both convenience and experience which make the close vicinity of settlements favorable for collection sites.

Figure 4 shows the association between use frequency and collection sites. Interestingly, the most often used species are not necessarily collected in the close vicinity of the villages. Two of the three daily-used ritual plants (Pinus yunnanensis and Cupressus funebris) are collected at higher altitudes in the $P$. yunnanensis forest and the conifer forest. Ritual plants from higher altitudes are preferred because they are perceived to be in close proximity to the mountain gods. The selection of ritual plant collection sites is thus strongly influenced by cultural factors. Still, some of the regularly used ritual plants, e.g., Pistacia weinmannifolia, are collected close to home, allowing sufficient sup- ply during busy times. The frequently used species are collected in six different vegetation zones, whereas the majority are collected in the close vicinity of the villages (Fig. 4). Again, some of the frequently used ritual plants $(\mathrm{Ju}$ niperus spp.) are collected at higher altitudes in the alpine shrub vegetation at $4,000 \mathrm{~m}$ and above.

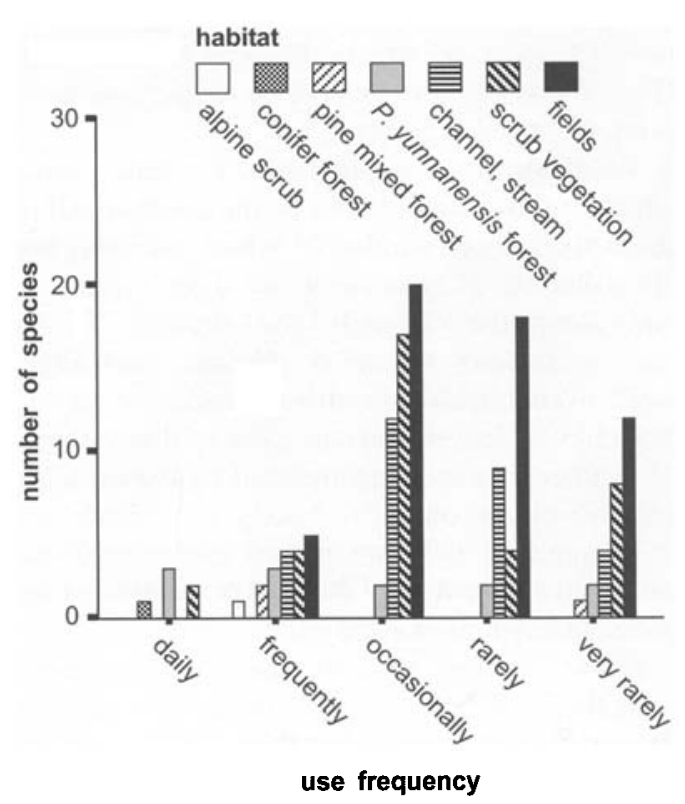

Fig. 4. Association between use frequency and collection sites of plant species. 


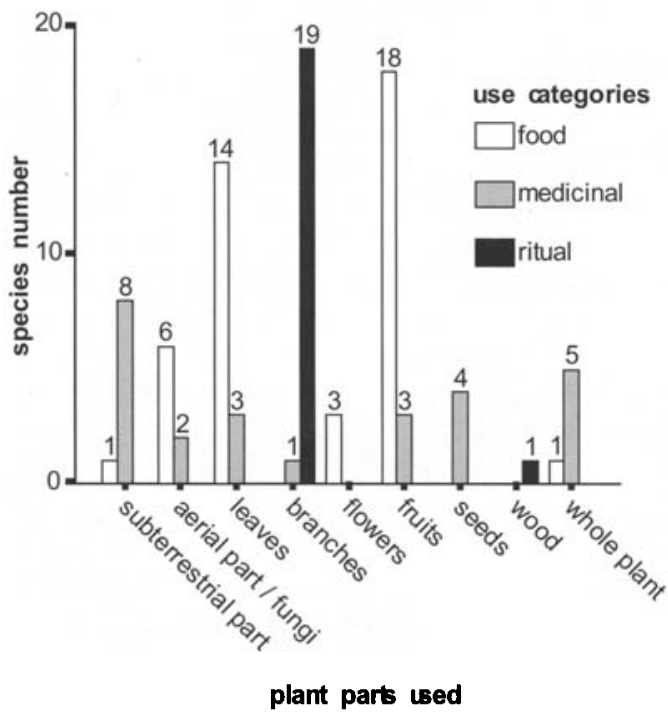

Fig. 5. Association between plant parts used and different use categories.

\section{Ritual Plants}

Ritual plants play an important role in the daily life of the Shuhi as well as in healing rituals of the dumbus. Ritual plants are used either to please the deities and assure their support of human health and well-being or to drive out malevolent spirits. The ritual plants are typically shrubs (17 spp.) or trees (3 spp.), of which the branches are used (Figs. 5 and 6). For one species (Cupressus funebris), the wood is gathered.

We recorded nine plant species, called lahu, which are exclusively used by the dumbus. All of these species are shrubs, of which the branches are collected. They occur in the shrub vegetation and along the channels and streams. Mahonia bracteolata, Rhamnus gilgiana, and Sageretia pycnophylla are characterized by thorny branches or leaves and are used to drive ghosts off. Either they are actively used by the ritualists to drive ghosts out of the body, the house, and the hamlet, or they are put on the ground and weighted down with a stone, e.g., under hamlet gates, to keep ghosts away.

In the past the ritualists made "little houses" with the branches of Salix cheilophila. One of the dumbus explained that these "little houses" were also used to drive ghosts away and were employed in the context of illnesses, conflicts, and funerals. However, they are no longer used today. Mueggler (2001:31) describes the prepa-

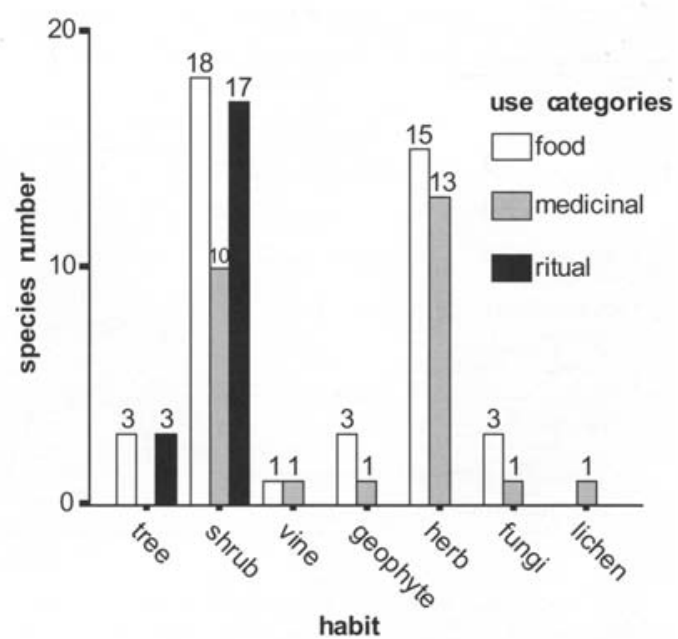

Fig. 6. Association between plant growth habit and different use categories.

ration of "ghost bodies" during rituals among the ethnic group of the Lolopo. For the construction of these sculptural representations of ghosts, the ends of three willow sticks are tied to an old sieve and bound together above it. They might resemble the "little houses" mentioned by the dumbu, which probably also functioned as effigies for the ghosts during the ritual.

Rhododendron decorum is another important plant used by the dumbus. Before each ritual the leaves are burned, the smoke being thought to clean the room or the environment where the ritual takes place. Additionally, the leaves provide an important device for the dumbu to remember his ritual texts, which, according to legend, have long been lost. He either touches a leaf with the tip of his tongue or just holds the leaves in his hands while reciting.

Most of the ritual plants commonly used by the local people are burned as incense to please the deities. Foremost among these are Pinus yunnanensis, Pistacia weinmannifolia, Cupressus funebris, and Juniperus spp. The first two are burned fresh, in a ritual burner or in the hearth; the last two are dried and burned in an incense bowl. The plants are burned to communicate with the gods and to offer them food, either in the form of good smell or as food offerings spread over the burning branches (e.g., tsampa, flour prepared from roasted barley grain, mixed with flowers of Tagetes erecta L.). White smoke is considered to be important for 
communication with the gods. Thus, there are two main criteria for the selection of ritual plants: their smell and the type of smoke they produce when burned.

A third criterion is the habitat of the plants. Since the high mountains represent the most important gods, ritual plants growing at high altitudes are preferred. Between Pinus yunnanensis and Pistacia weinmannifolia, which both can be burned in the ritual burner on the flat roof of the houses during the daily morning ritual, pine is claimed to be the better choice, since it grows on higher altitudes. Pistacia, however, grows close to the villages and is therefore often used during busy times. Quercus guajavifolia and Aster lavandulifolius can also be used instead.

Cupressus funebris and Juniperus spp. are collected in the conifer mixed forest $(3,500$ $4,400 \mathrm{~m})$ and the alpine shrub vegetation (above 4,000-4,500 m), respectively. While the latter species is usually bartered from people of other ethnic groups, who either herd yaks at high altitudes or who are doing some pilgrimage to the holy mountains, Cupressus funebris is collected by the Shuhi themselves. The Shuhi of Lanman village, for example, collect the wood in the forests surrounding their village mountain god. Once or twice a year, groups of persons from different households go to collect wood of old fallen trees, because it is not allowed to cut trees in forests close to the mountain tops, and, additionally, old wood produces the best smell when burned.

Another group of ritual plants is not burned but used for the decoration of special places in and outside the house, such as the door, the yatze (little stone towers on the flat roofs of the houses), the pillars in the living room, the tala (the holy place behind the hearth), the house altar, and places outside, such as the water god place. Branches of Cornus oblonga, Pinus yunnanensis, Pistacia weinmannifolia, Tagetes erecta, and Phyllostachys sp. are placed at these holy places to invite the deities. Most of the species used are evergreen, a property which was claimed to be especially appreciated by the deities. During the Tibetan New Year, all the plants are renewed. However, on other occasions as well during the year fresh plants are mounted, e.g., during the harvest festivals in spring and autumn, or for special rituals performed by individual households.

\section{Medicinal Plants}

Wild collected medicinal plants for primary health care in rural communities and as an income source are important in many regions of the Himalaya (e.g., Bhattarai 1989; Joshi and Joshi 2000; Huang, Pei, and Long 2004; Sharma, Chauhan, and Lal 2004). Overall the uses of 27 medicinal plants have been recorded for the Shuhi. Like the wild food plants, most of the medicinal plants are collected in the near vicinity of the villages: in the fields $(63 \%)$, in the shrub vegetation (22\%), and along the channels and streams (7\%). Papaver somniferum L. is the only medicinal plant which is cultivated in the fields. Herbs (13 spp.) and shrubs (10 spp.) are the predominant source of plant medicine (Fig. 6).

In contrast to wild collected food, which mainly consists of fruits or leaves, underground plant parts play an important role in the preparation of medicine. Among the Shuhi, subterranean parts ( $8 \mathrm{spp}$.), fruits and seeds (7 spp.), leaves or branches (4 spp.), or the whole plants (5 spp.) are used in similar proportion (Fig. 5). Underground plant parts are commonly used in the Sino-Himalayan area. While some studies document the medicinal use of different plant parts to equal degrees (Bhattarai 1989; Huai and Pei 2004; Huang, Pei, and Long 2004), others stress the predominant use of underground parts (Shrestha and Dhillion 2003; Sharma, Chauhan, and Lal 2004) or the whole plant (Navachoo and Buth 1989; Long and Li 2004). Roots are known to contain high concentrations of bioactive compounds, thus tending to be more pharmacologically potent or even toxic than leaves are (Johns 1990:259).

Most of the documented medicinal remedies are based on the preparation of a single plant, and by far the most often recorded preparation mode (67\% of the species) is decoction for internal use. Sometimes a decoction of two or three plants together is prepared, e.g., of Gyrtomium falcatum and Mentha spicata to treat cough and sore throat, or Acorus calamus, Rumex nepalensis, and Valeriana jatamansi for a stomachache. Rarely, smoke is inhaled (e.g., of the seeds of Datura stramonium for a toothache), or fresh plant material or decoctions are used for external applications (e.g., decoction of Wikstroemia delavayi as analgesic). Overall, $37 \%$ of the species are used to treat 
gastrointestinal problems such as diarrhea, constipation, stomachache, and parasites, and $26 \%$ are used to treat respiratory tract infections such as cold, cough, and sore throat. To a lesser extent, plants are used to treat wounds and genital-urinary ailments, for dental care, or as a tonic.

These findings correspond to other studies in the Sino-Himalayan area, which show that the most frequent treatments with medicinal plants involve the digestive system (Joshi and Joshi 2000; Huang, Pei, and Long 2004) and the respiratory system (Shrestha and Dhillion 2003). However, in some places a relatively high number of medicinal plants are known to treat dermatological illnesses (Joshi and Joshi 2000; Huai and Pei 2004; Huang, Pei, and Long 2004), broken bones (Huai and Pei 2004; Huang, Pei, and Long 2004), or fever (Bhattarai 1989). The number of known remedies in a certain area most likely reflects the commonly contracted diseases. For example, dermatological illnesses are more likely to occur in warm and humid areas, and, accordingly, in those areas more medicinal plants are known to cure these diseases (Joshi and Joshi 2000; Huai and Pei 2004; Huang, Pei, and Long 2004).

The recorded information on medicinal plants was compared with literature on Chinese medicinal plants (Compilation of Chinese Herb Medicine 1976-1978) and ethnobotanical surveys from other Sino-Himalayan areas. Besides four species (Cyrtomium falcatum, Mahonia bracteolata, Rosa soulieana, and Wikstroemia delavayi) of which closely allied taxa are known to be used as medicinal plants, all of the recorded species are used for similar purposes in other parts of China and the Himalayan area. The pharmacological literature supports the effectiveness of the most often mentioned species, i.e., Acorus calamus, Rumex nepalensis, and Valeriana jatamansi. Acorus calamus has been positively tested for its antidiarrheal effect (Shoba and Thomas 2001), while the purgative effects of the roots of Rumex nepalensis have also been affirmed (Ghosh et al. 2003). Valeriana jatamansi is a critically endangered medicinal plant in Western Himalaya (e.g., Airi et al. 2000; Rai, Prasad, and Sharma 2000). Much like other Valeriana spp., the major recorded uses are as a tranquilizer and CNS sedative and as a treatment for gastrointestinal hyperactivity, both of which are approved in pharmacological studies (Houghton 1999). The Shuhi, however, only mentioned its use to treat a stomachache.

Among the medicinal plants, six species (Mahonia bracteolata, Paeonia delavayi, Polygonatum cirrhifolium, Prinsepia utilis, Vitis betulifolia, and Prunus sp.) are occasionally collected for trade. While the first three are collected for their roots or rhizomes, the seeds of the last three are sold. Due to overharvesting, the trade of Mahonia bracteolata roots was banned several years ago. The other species, however, are occasionally collected when traders from outside the valley request them. The demand seems to vary greatly from year to year, so medicinal plant collection is not a regular source of income for the Shuhi.

Compared with other studies, relatively few medicinal plants and preparation modes have been recorded for the Shuhi. Other small-scale studies in the area, which are based on interviews with local people and specialists (herbalists, traditional healers), usually record between 45 and 65 species (e.g., Manandhar 1998; Joshi and Joshi 2000; Huang, Pei, and Long 2004), while our study only documents the use of 27 species. The Shuhi people have no herbalists, and all of the interviewed persons stated that they do not have, and have never had, a tradition of using medicinal plants. They claimed that they borrowed their knowledge from surrounding ethnic groups such as the Bai, Han, Miao, and Tibetans. As noted, traditional healers among the Shuhi are the dumbus, specialists who use ritual practices and other methods for healing instead of medicinal plants.

All key informants mentioned that there was a general increase in the use of medicinal plants in the 1960s and 1970s, during the time of the so-called barefoot doctors. To improve primary health care in the rural areas, the state organized basic medical training for farmers. Barefoot doctors were given a set of medicines, Chinese and Western, that they would dispense. Often they grew their own herbs in the backyard. However, according to key informants, there was not much knowledge transfer between the barefoot doctors and the local people, so the overall medicinal plant knowledge did not change significantly. Not surprisingly, therefore, medicinal plants seem to be used very rarely these days. Instead, the few village doctors in the area sell allopathic drugs. The 
usual treatment for most diseases consists of a penicillin injection. All interviewed persons mentioned that they prefer to use allopathic drugs instead of medicinal plants, both because of a lack of knowledge about plant medicine and because it is easier to buy the medicine than to prepare it at home. However, several claimed interest in information about effective and easy to use medicinal plants. In addition to Western medicine, ritual healing practices are still widely applied. While some of the interviewees mentioned that they call a ritualist in the case of serious illnesses, others prefer to invite them for minor illnesses.

\section{Food Plants}

Wild edible plants are an important constituent of traditional diets in Himalayan areas as sources of proteins, sugars, vitamins, and minerals (Samant and Dhar 1997; Sundriyal and Sundriyal 2001). Among the Shuhi, we documented 43 wild culinary or food plants. Most of these are collected near the villages: in the fields (42\%), along the channels and streams $(28 \%)$, and in the shrub vegetation (21\%). Plants of which the fruits are eaten represent the largest number of species (18 spp.), followed by leafy vegetables (15 spp.; leaves and shoots of herbs or geophytes). Rarely, people consume the whole plant ( $1 \mathrm{sp}$.), subterranean parts (1 sp.), leaves collected from shrubs or trees ( $2 \mathrm{spp}$.), flowers ( $3 \mathrm{spp}$.), or fungi (3 spp.) (Figs. 5 and 6).

The marked preference for wild collected fruits and leafy vegetables over underground plant parts seems to be common among various ethnic groups in China and the Himalayan area and might be due to the ease of the collection of aerial plant parts. Chen et al. (1999) and $\mathrm{Xu}$ et al. (2004) give an overview of wild collected edible plants in Xishuangbanna, southern Yunnan (China). Wild collected fruits and leafy vegetables are highly diverse, while plants which are consumed for their underground parts make up only a few percent of the overall species number $(6 \%$ in $\mathrm{Xu}$ et al. 2004). Similar patterns are found among Inner Mongolian herdsmen (Khasbagan, Huai, and Pei 2000), in the Sikkim Himalaya area for low $(300-900 \mathrm{~m})$ as well as high elevations $(>2,000 \mathrm{~m}$; Sundriyal, Sundriyal, and Sharam 2004), and in an overview of wild collected food plants of the Indian Himalaya (Samant and Dhar 1997). Whether the fruiting species or the leafy vegetables are more diverse seems to vary from region to region, but this might also reflect the methodology used by researchers.

The Shuhi consume most of the wild fruits fresh, as snacks eaten while on their way to the fields, forest, etc. They are collected from shrubs and rarely from trees (Diospyros lotus and Morus alba) or vines (Vitis betulifolia). Fruits might also be collected for young children at home (e.g., Rubus parvifolius or Sageretia pycnophylla) or for conservation through drying (e.g., Diospyros lotus). Few fruits are used for cooking. The fresh or dried fruits of Zanthoxylum armatum are used as spice for vegetable dishes and the fruits of Ficus sarmentosa are sometimes cooked with rice. Almost half of the species ( $8 \mathrm{spp}$.) are exclusively collected for their edible fruits. The others are used multicontextually, e.g., the fruits or seeds are also used as medicine (Zanthoxylum armatum, Vitis betulifolia, and $O p$ untia ficus-indica), the branches for rituals (Cornus capitata, Rhamnus gilgiana, Sageretia pycnophylla), the branches and leaves as fodder (Opuntia ficus-indica, Morus alba, and Ficus sarmentosa), or the wood as fuel (Diospyros lotus).

The daily diet of the Shuhi mainly consists of cooked rice, preserved pork, and chili (Capsicum annuum L.). Before each meal, butter tea together with tsampa is served. Other than chili, few vegetables are cultivated and consumed. The most widely used vegetable is cabbage leaves, which are usually cooked in water and served as soup. Instead of the cultivated cabbage leaves, leaves or shoots of wild collected herbs are occasionally cooked, e.g., Chenopodium album, Sonchus oleraceus, or Stellaria media.

Wild leafy vegetables seem to be rarely used among the Shuhi. Several elderly people mentioned that they were mainly eaten in the past during times of food shortage. However, some are regularly consumed during springtime: Epilobium hirsutum (young shoots), Mentha spicata (young shoots), Houttuynia cordata (whole plant including rhizomes), Toona sinensis (young leaves), and Pteridium aquilinum (young shoots). The first three are consumed fresh with chili. Toona sinensis leaves are consumed fresh or cooked, and the Pteridium 
aquilinum shoots have to be detoxified before consumption; they are cooked over the fire in periodically renewed water for several hours. The consumption of Houttuynia cordata, Toona sinensis, and Pteridium aquilinum as wild vegetables is common in many parts of China (personal observation).

Like wild collected fruits, leaves might also be dried for consumption during the winter. This use was especially mentioned for the leaves of Arisaema flavum, a geophyte (perennial plant with underground buds) flowering during June and July and not consumed fresh. The mature leaves of the plant are collected in autumn and dried for consumption during the winter. There are several other Arisaema species growing in the same habitat, which, however, were described as toxic, causing the swelling of lips and tongue.

Nine species are consumed exclusively as leafy vegetables. The remaining species are used additionally either as medicine or as fodder. For example, the roots of Acorus calamus, Mentha spicata, Sonchus oleraceus, and Valeriana jatamansi are occasionally used to prepare decoctions against cold, stomachache, and diarrhea. If the leaves of Sonchus oleraceus are consumed as a vegetable, the first decoction is poured away, since it is too bitter. It is, however, this first decoction which can be used as medicine for a cold or stomachache. The old leaves of Chenopodium album and Heracleum burmanicum aff. are collected and cooked as pig's fodder. Multicontextual use of species, especially a continuum between medicinal and food plants, is a phenomenon found all over the world (e.g., Johns et al. 1999; Bonet and Vallès 2002; Scherrer, Motti, and Weckerle 2005) and might reflect the joint origin of human diet and medicine (Johns 1990:285-287).

Mainly two fungi, Auricularia auriculajudae and Lentinula edodes, are used fresh or dried. They occur near the villages in the vegetation along the channels. Tricholoma matsutake is collected for trade. It is found in the mixed pine forest and is collected during July and August by middle-aged household members. It is a highly valuable fungus and an important source of cash income for the households.

Allium macrostemon and Houttuynia cordata are the only species of which the whole plant or underground parts are consumed as vegetables.
Chelonopsis mollissima and Silene napuligera flowers are often sucked for their nectar, and occasionally flowers of Rhododendron yunnanense are eaten as snacks.

\section{Conclusions}

First, in the Shuhi community ritual plants play an important role in human well-being. Both cleaning the environment of malevolent spirits and pleasing the deities are considered essential for health and are achieved by using various kinds of plants. Although ritual plants are used daily, they are preferentially collected in habitats at high altitudes close to the mountain gods. Thus, habitat selection of this plant category is strongly influenced by cultural values.

Second, the knowledge of the Shuhi regarding wild food plants is comparable with other ethnic groups in the Sino-Himalayan area. The food plants mainly consist of wild collected fruits and leafy vegetables, some of which are regularly consumed during springtime. However, medicinal plant knowledge is relatively limited, probably due to the fact that traditional Shuhi healers use ritual and other healing methods instead of medicinal plants. We therefore conclude that although the Shuhi live in an area known for its medicinal plant richness, their traditional healing system is not based on medicinal plants.

Third, all habitats from the dry shrub vegetation at the valley bottom up to the alpine shrub are used for plant collection, but $87 \%$ of all species are collected in the near vicinity of the villages, around the fields and in the dry shrub vegetation. This can be explained by convenience as well as the experience of the people that habitats close to human settlements contain a high diversity of useful plants.

Therefore we postulate two main factors influencing wild plant use of the Shuhi: cultural values and accessibility. Cultural values have a strong effect on the use and collection of ritual and healing plants, whereas accessibility is more likely to affect the utilization of plants of other categories.

\section{ACKNOWLedgments}

We are very grateful to all the inhabitants of the Shuiluo area for their openness and hospitality. We thank Elisabeth Hsu and Zhang Shiya, who initiated and enabled research in the 
Shuiluo Valley. Moreover, we thank Xiao Wang, Gao Fu, Chen Yulin, Li Ting, Markus Schiesser, Roland Naef, and Beatrix Nüscheler for their help in many aspects of the fieldwork, Wu Sugong and Andrew Willson for critical comments on the manuscript. The project has been funded by the Ciba Research Foundation, Switzerland, and the Swiss National Science Foundation PBZHA-104354.

\section{Literature Cited}

Airi, S., R.S. Rawal, U. Dhar, and A. N. Purohit. 2000. Assessment of availability and habitat: Preference of Jatamansi--A critically endangered medicinal plant of west Himalaya. Current Science 79:1467-1471.

Baumer, C. 1999. Bön: Die lebendige Ur-Religion Tibets. Akademische Druck- und Verlagsanstalt, Graz, Austria.

- and T. Weber. 2002. Ost-Tibet. Brücke zwischen Tibet und China. Akademische Druck- und Verlagsanstalt, Graz, Austria.

Benz, B.F., J. E. Cevallos, F. M. Santana, J. A. Rosales, and S.M. Graf. 2000. Losing knowledge about plant use in the Sierra de Manantlan biosphere reserve, Mexico. Economic Botany 54:183191.

Berlin, B. 1992. Ethnobiological classification. Principles of categorization of plants and animals in traditional societies. Princeton University Press, Princeton, New Jersey.

Bhattarai, N.K. 1989. Traditional phytotherapy among the Sherpas of Helambu, Central Nepal. Journal of Ethnopharmacology 27:45-54.

Bonet, M. A., and J. Vallès. 2002. Use of non-crop food vascular plants in Montseny biosphere reserve (Catalonia, Iberian Peninsula). International Journal of Food Sciences and Nutrition 53:225248.

Chen, J., Y.C. Su, G. Q. Chen, and W. D. Wang. 1999. Ethnobotanical studies on wild edible fruits in southern Yunnan: Folk names, nutritional values and uses. Economic Botany 53:2-14.

Compilation of Chinese Herb Medicine Editorial Committee, eds. 1976-1978. Compilation of Chinese herb medicine. Vols. 1-2. People's Health Publishing Company, Beijing. (Chinese)

Flora of China Editorial Committee, eds. 1994 to present. Flora of China. Science Press, Beijing, and Missouri Botanical Garden Press, St. Louis.

Ghimire, S.K., D. McKey, and Y. AumeeruddyThomas. 2005. Conservation of Himalayan medicinal plants: Harvesting patterns and ecology of two threatened species, Nardostachys grandiflora DC. and Neopicrorhiza scrophulariiflora (Pennell) Hong. Biological Conservation 124:463475.
Ghosh, L., J. R. Gayen, T. Murugesan, S. Sinha, M. Pal, and B.P. Saha. 2003. Evaluation of purgative activity of roots of Rumex nepalensis. Fitoterapia 74:372-374.

Handel-Mazzetti, H. 1921. Übersicht über die wichtigsten Vegetationsstufen und -formationen von Yünnan und Südwest Setschuan. Botanische Jahrbücher 54:578-597.

Houghton, P. J. 1999. The scientific basis for the reputed activity of valerian. Journal of Pharmacy and Pharmacology 51:505-512.

Hsu, E. 1998. Introduction. Pages 9-19 in M. Oppitz, and E. Hsu, eds. Naxi and Moso ethnography: Kin, rites, pictographs. Völkerkundemuseum deI Universität Zürich, Zürich, Switzerland.

Huai, H. Y., and S. J. Pei. 2004. Plants used medicinally by folk healers of the Lahu people from the autonomous county of Jinping Miao, Yao, and Dai in southwest China. Economic Botany 58 (Supplement):S265-S273.

Huang, J., S. J. Pei, and C. L. Long. 2004. An ethnobotanical study of medicinal plants used by the Lisu people in Nujiang, northwest Yunnan, China Economic Botany 58 (Supplement):S253-S264 Johns, T. 1990. With bitter herbs they shall eat it Chemical ecology and the origins of human die and medicine. University of Arizona Press, Tuc. son.

, R. L. A. Mahunnah, P. Sanaya, L. Chapman and T. Ticktin. 1999. Saponins and phenolic con tent in plant dietary additives of a traditional sub sistence community, the Batemi of Ngorongorc District, Tanzania. Journal of Ethnopharmacology 66:1-10.

Joshi, A. R., and K. Joshi. 2000. Indigenous knowl edge and uses of medicinal plants by local com munities of the Kali Gandaki Watershed area Nepal. Journal of Ethnopharmacology 73:175183.

Kala, C.P. 2000. Status and conservation of rare anc endangered medicinal plants in the Indian Trans Himalaya. Biological Conservation 93:371-379

Khasbagan, H.Y. Huai, and S.J. Pei. 2000. Wili plants in the diet of Arhorchin Mongol herdsmes in Inner Mongolia. Economic Botany 54:528-536

Long, C.L., K. Cai, K. Marr, X.R. Guo, and Z.Q Ouyang. 2003. Lacquer-based agroforestry sys tem in western Yunnan, China. Agroforestry Sys tems 57:109-116.

-, and R. Li. 2004. Ethnobotanical studies o medicinal plants used by the Red-headed Ya People in Jinping, Yunnan Province, China. Jour nal of Ethnopharmacology 90:389-395.

$\mathrm{Ma}$, Shuji (one of the main officials from the Shuilu Township). 1996. Personal communication.

Manandhar, N.P. 1998. Native phytotherapy amon the Raute tribes of Dadeldhura district, Nepa Journal of Ethnopharmacology 60:199-206. 
Morell, V. 2002. China hotspot. National Geographic 201:98-113.

Mueggler, E. 2001. The age of wild ghosts. Memory, violence, and place in southwest China. University of California Press, Berkeley.

Myers, N., R. A. Mittermeier, C.G. Mittermeier, G. A. B. da Fonseca, and J. Kent. 2000. Biodiversity hotspots for conservation priorities. Nature 403:853-858.

Navchoo, I. A., and G. M. Buth. 1989. Medical system of Ladakh, India. Journal of Ethnopharmacology 26:137-146.

Olson, D. M., and E. Dinerstein. 2002. The global 200: Priority ecoregions for global conservation. Annals of the Missouri Botanical Garden 89:199_ 224.

Pei, S. J., Y.H. Li, and S.Z. Yin. 1996. Ethnobotanical investigation of plant drugs at local markets in north-west Yunnan of China. Pages 150-169 in S.J. Pei, Y.G. Su, C.L. Long et al., eds. Proceedings of the second international congress of ethnobiology. Yunnan Science and Technology Press, Kunming, China.

Rai, L. K., P. Prasad, and E. Sharma. 2000. Conservation threats to some important medicinal plants of the Sikkim Himalaya. Biological Conservation 93:27-33.

Salick, J., A. Biun, G. Martin, L. Apin, and R. Beaman. 1999. Whence useful plants? A direct relationship between biodiversity and useful plants among the Dusun of Mt. Kinabalu. Biodiversity and Conservation 8:797-818.

—, D. Anderson, J. Woo, R. Sherman, N. Cili, Ana, and S. Dorje. 2004. Bridging scales and epistemologies: Linking local knowledge and global science in multi-scale assessments. Millennium Ecosystem Assessment, Alexandria, Egypt, March 17-20:1-12.

Samant, S.S., and U. Dhar. 1997. Diversity, endemism and economic potential of wild edible plants of Indian Himalaya. International Journal of Sustainable Development and World Ecology 4:179-191.

Saxena, K. G., K.S. Rao, K. K. Sen, R. K. Maikhuri, and R.L. Semwal. 2001. Integrated natural resource management: approaches and lessons from the Himalaya. Conservation Ecology 5:14. [online] URL: http://www.consecol.org/vol5/iss2/art14/.

Scherrer, A. M., R. Motti, and C. S. Weckerle. 2005. Traditional plant use in the areas of Monte Vesole and Ascea, Cilento National Park (Campania, Southern Italy). Journal of Ethnopharmacology 97:129-143.

Sharma, P. K., N. S. Chauhan, and B. Lal. 2004. Observations on the traditional phytotherapy among the inhabitants of Parvati valley in western Himalaya, India. Journal of Ethnopharmacology 92:167-176.

Shoba, F. G., and M. Thomas. 2001. Study of antidiarrhoeal activity of four medicinal plants in castor-oil induced diarrhoea. Journal of Ethnopharmacology 76:73-76.

Shrestha, P. M., and S.S. Dhillion. 2003. Medicinal plant diversity and use in the highlands of Dolakha district, Nepal. Journal of Ethnopharmacology 86:81-96.

Sun, H. K. 1990. Languages of the ethnic corridor in western Sichuan. Linguistics of the TibetoBurman Area 13:1-31.

Sundriyal, M., and R.C. Sundriyal. 2001. Wild edible plants from the Sikkim Himalaya: Nutritive values of selected species. Economic Botany 55:377-390.

$\longrightarrow$, R. C. Sundriyal, and E. Sharam. 2004. Dietary use of wild plant resources in the Sikkim Himalaya, India. Economic Botany 58:626638.

The International Plant Names Index (2004). Published on the Internet http://www.ipni.org (accessed October 2005).

Wang, C. 1961. The forests of China with a survey of grasslands and desert vegetation. Maria Moors Cabot Foundation Publication 5. Harvard University Press, Cambridge, Massachusetts.

Wang, W. T., S. G. Wu, K. Y. Lang, P. Q. Li, F. T. Pu, and S. K. Chen, eds. 1994. Vascular plants of the Hengduan Mountains. Vols. 1-2. Science Press, Beijing.

Wang, X. P., Z.H. Yang, J. S. Hong, I. Kunio, Y.S. Kim, A.C. Hamilton, and S. D. Davis. 1995. Regional overview: China and East Asia. Pages 145197 in S.D. Davis, V.H. Heywood, and A.C. Hamilton, eds. Centers of plant diversity. Vol 2. Information Press, Oxford.

Weckerle, C. S., F. K. Huber, Y.P. Yang, and W. B. Sun. 2005a. Walnuts among the Shuhi in Shuiluo, eastern Himalayas. Economic Botany 59(3):287290.

-, F. K Huber, Y.P. Yang, and W. B. Sun. 2005b. The role of barley among the Shuhi in the Tibetan Cultural Area of the eastern Himalayas. Economic Botany 59(4):386-390.

Weng, N.Q. 2005. Personal communication. Professor at the Institute of Ethnology and Anthropology, The Chinese Academy of Social Sciences, Beijing.

Xu, Y. K., G. D. Tao, H. M. Liu, K. L. Yan, and X.S. Dao. 2004. Wild vegetable resources and market survey in Xishuangbanna, Southwest China. Economic Botany 58:647-667. 


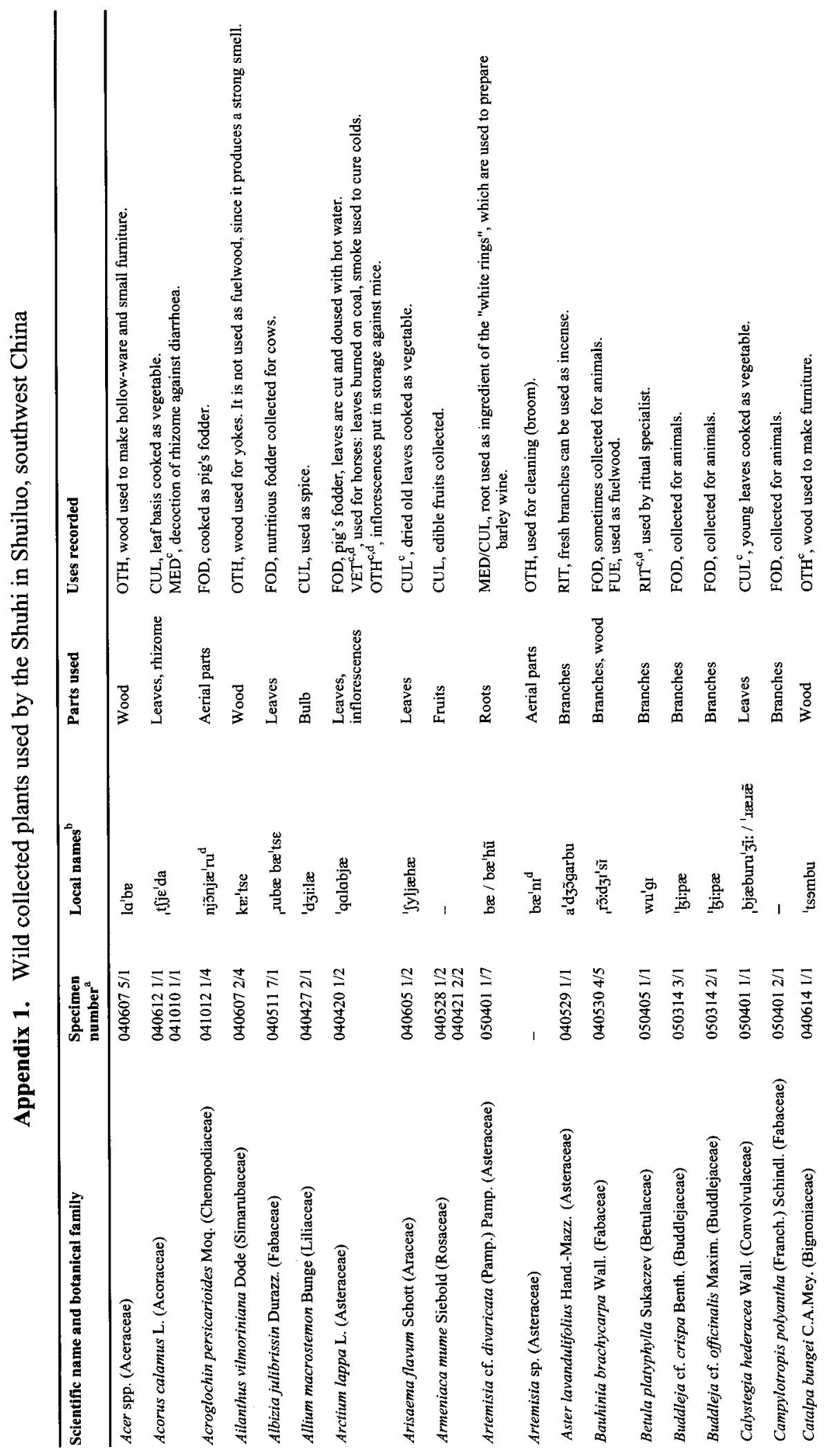




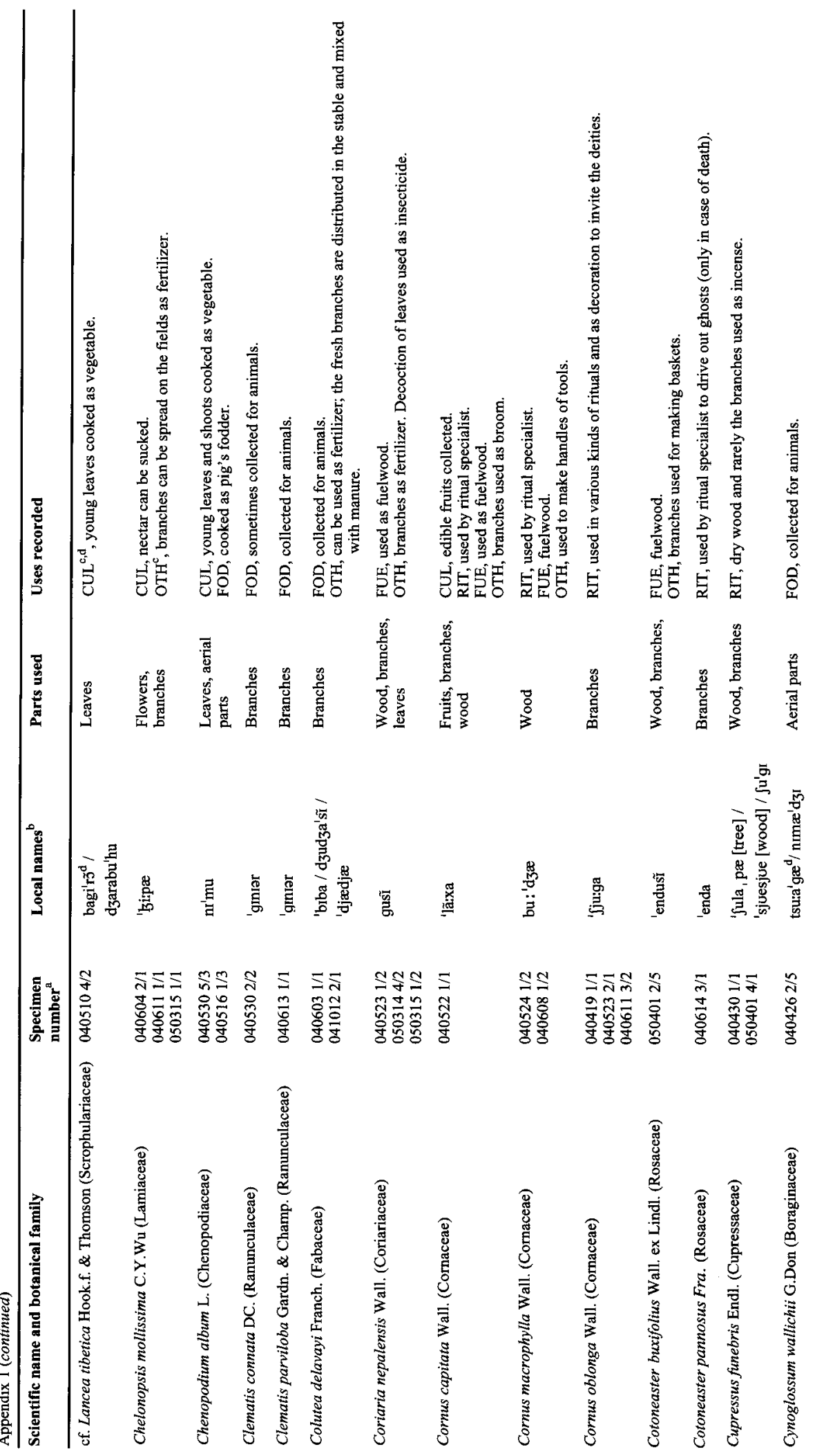




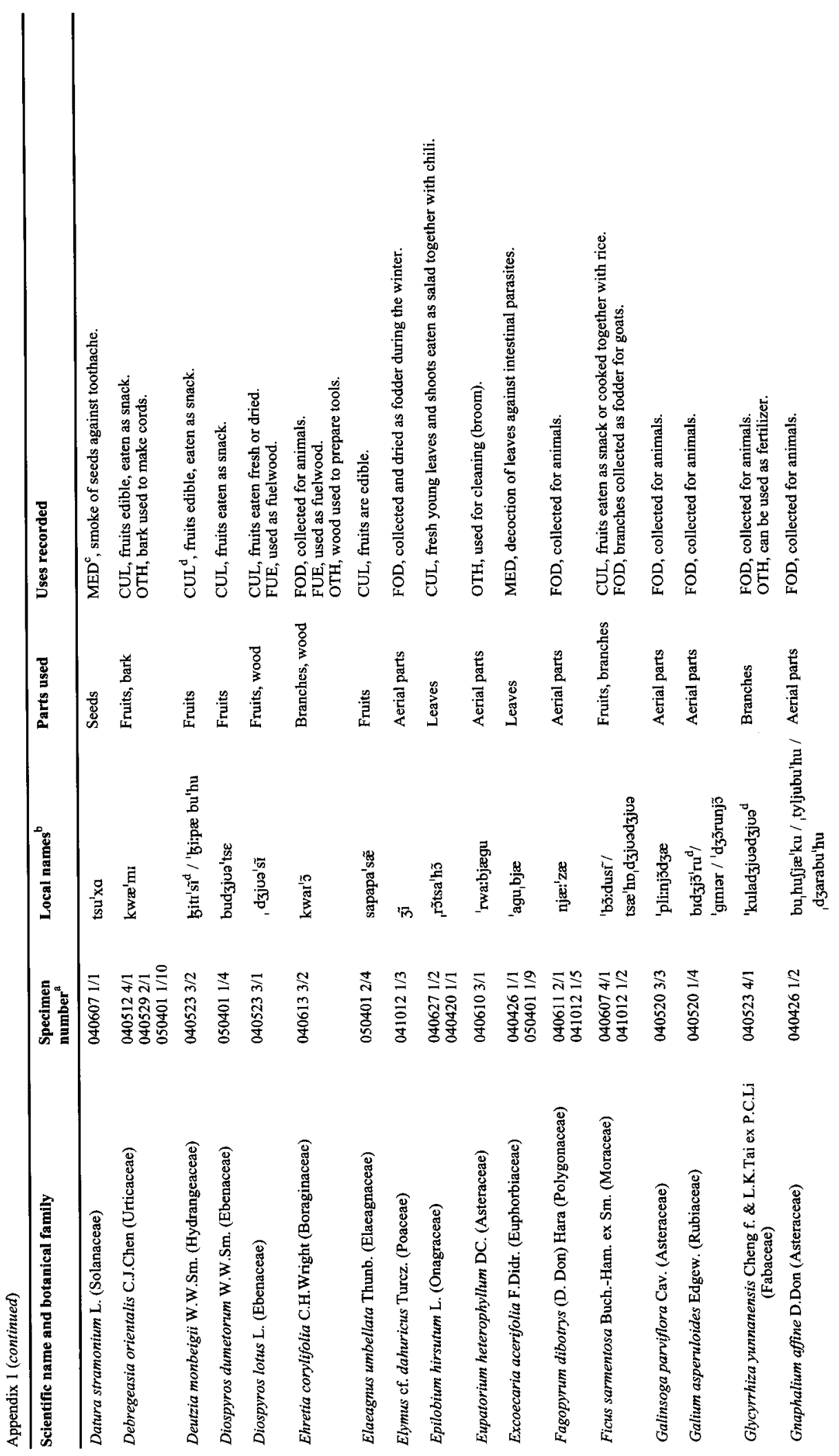




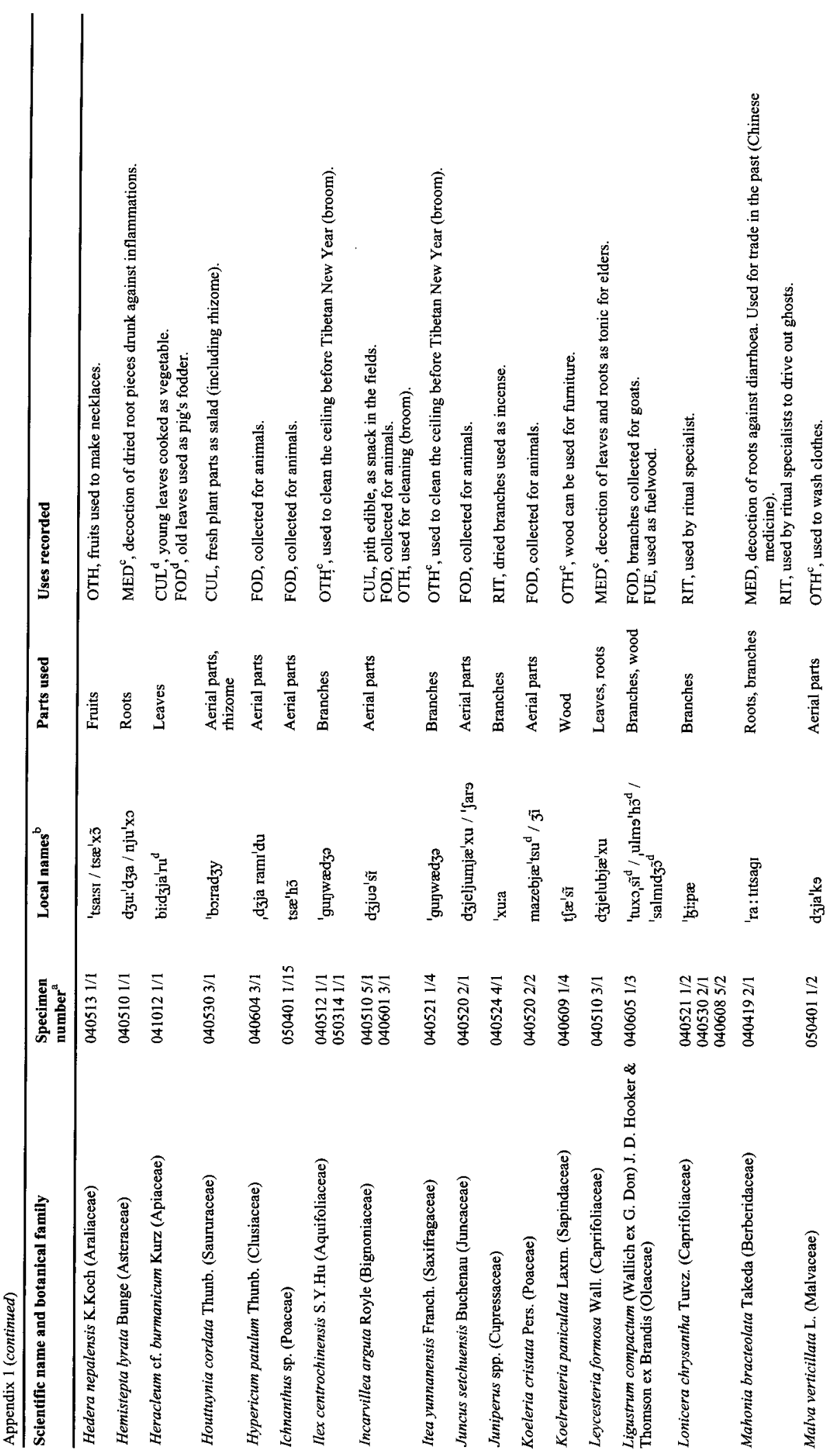




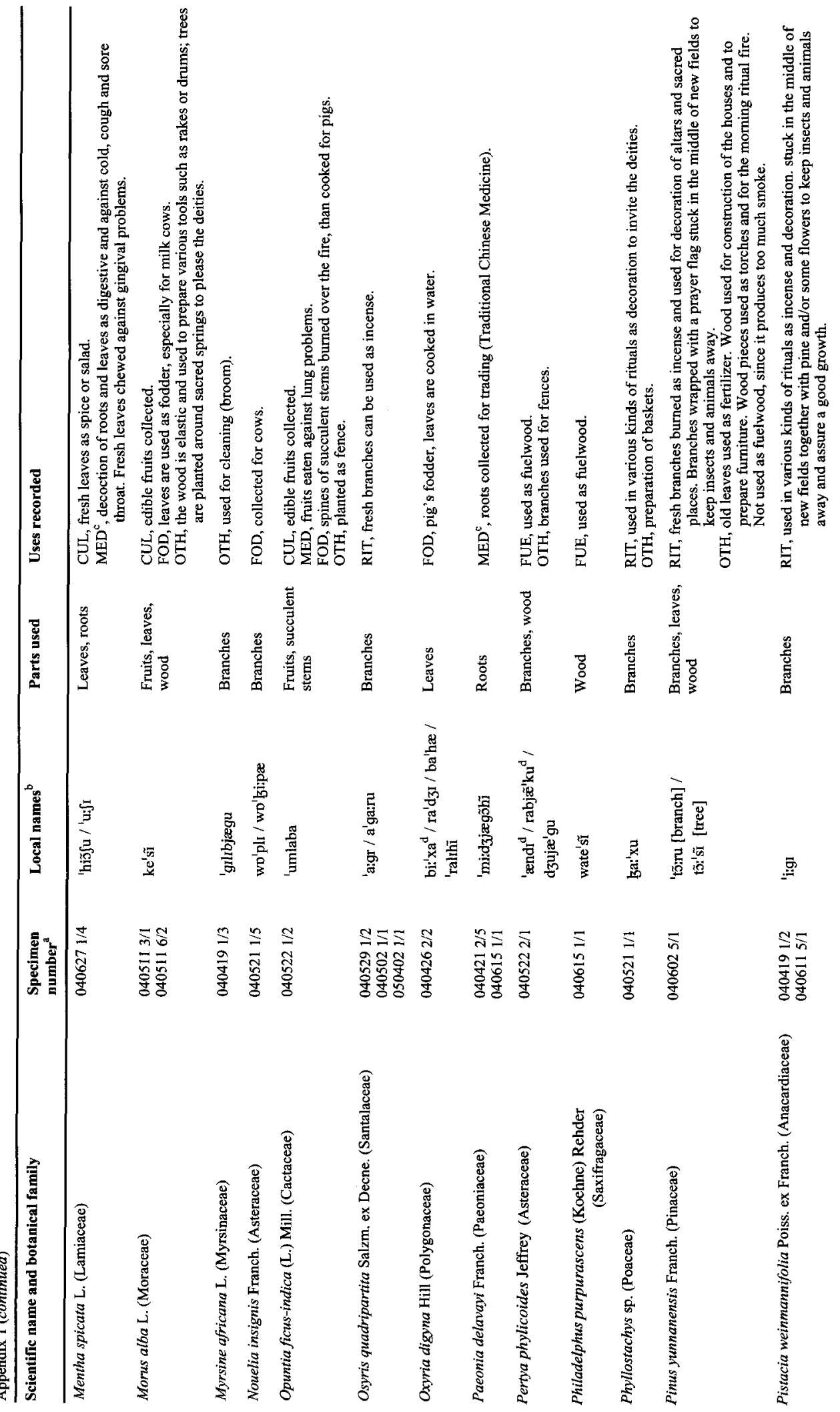




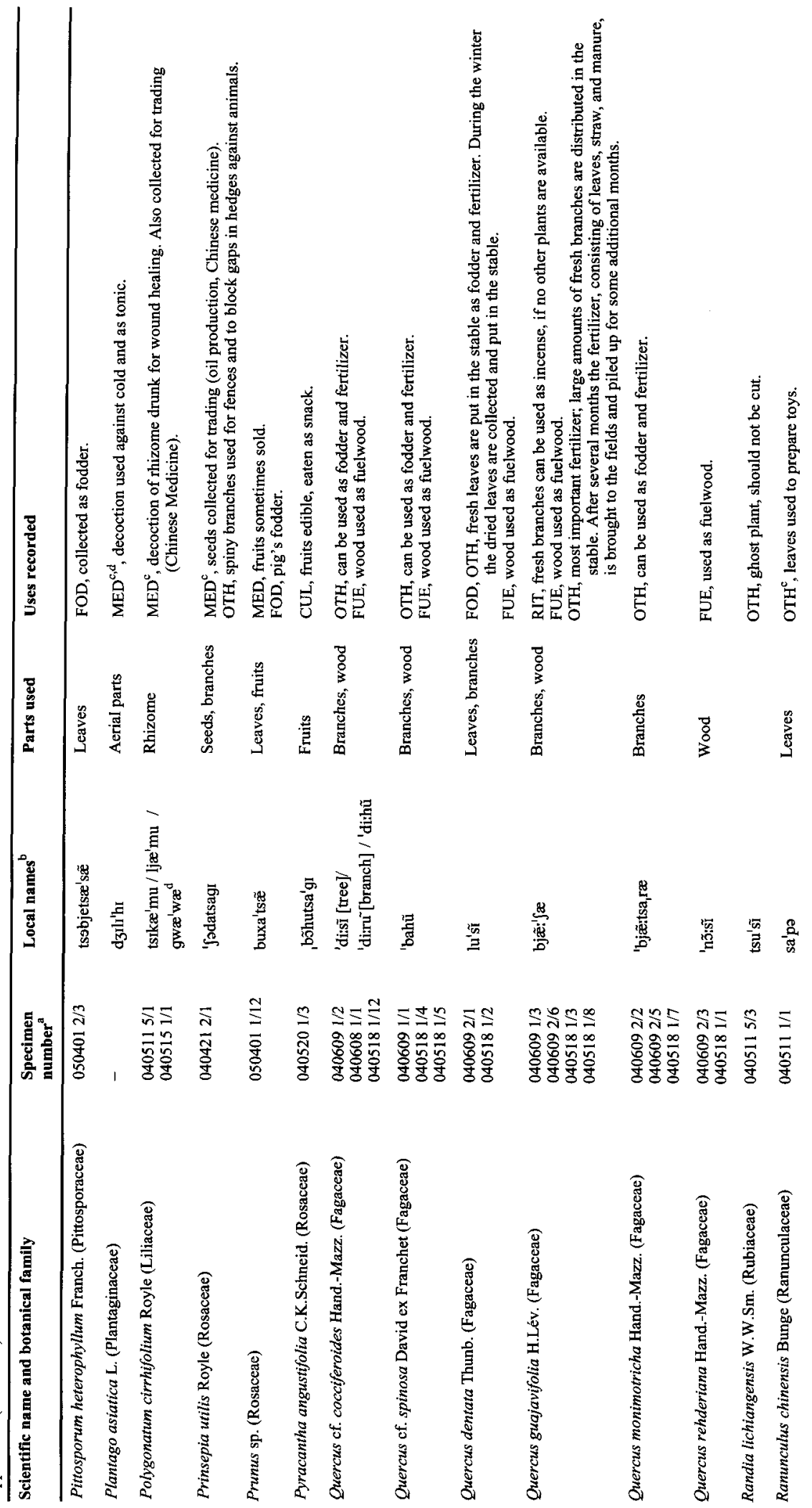




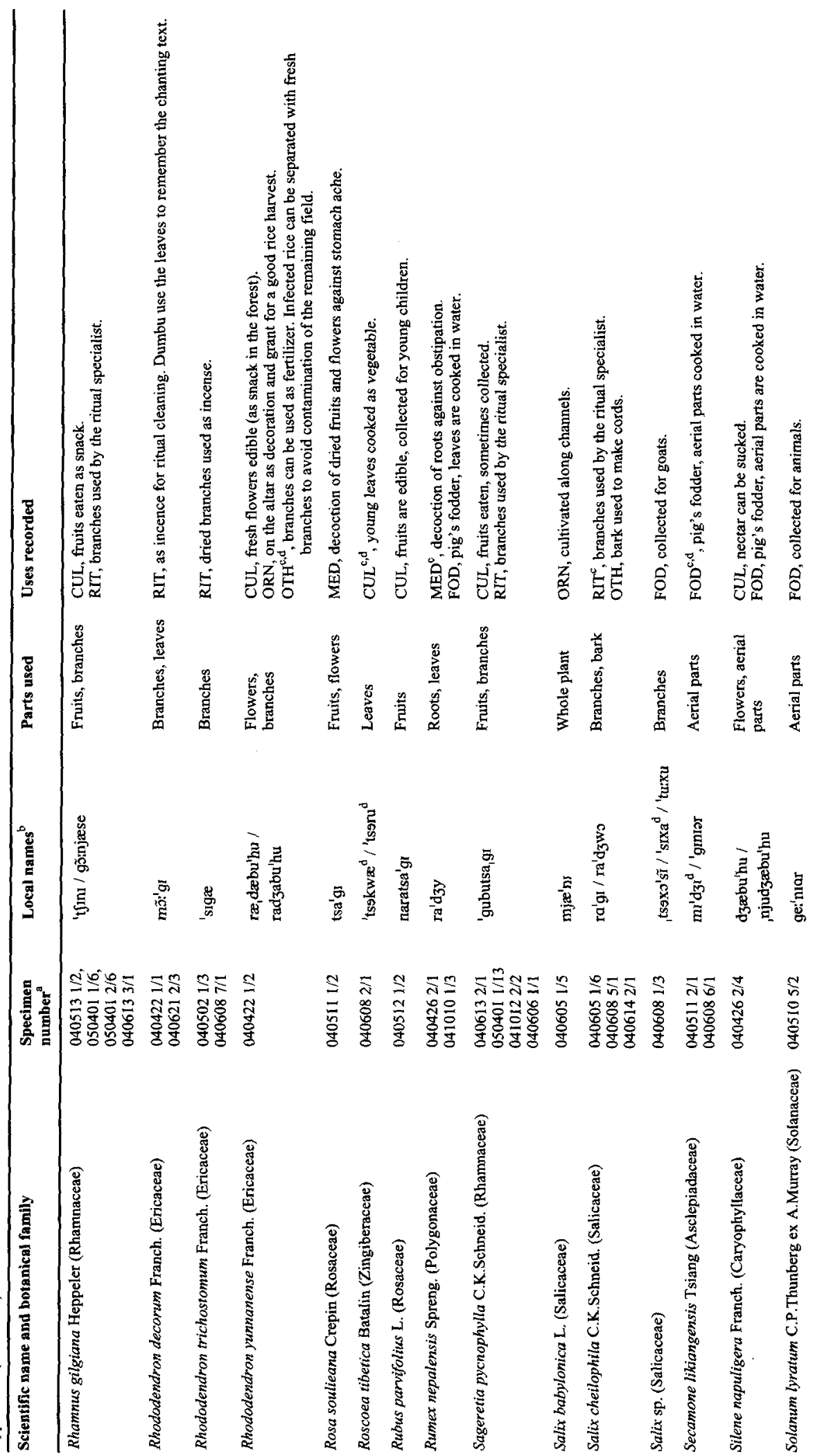




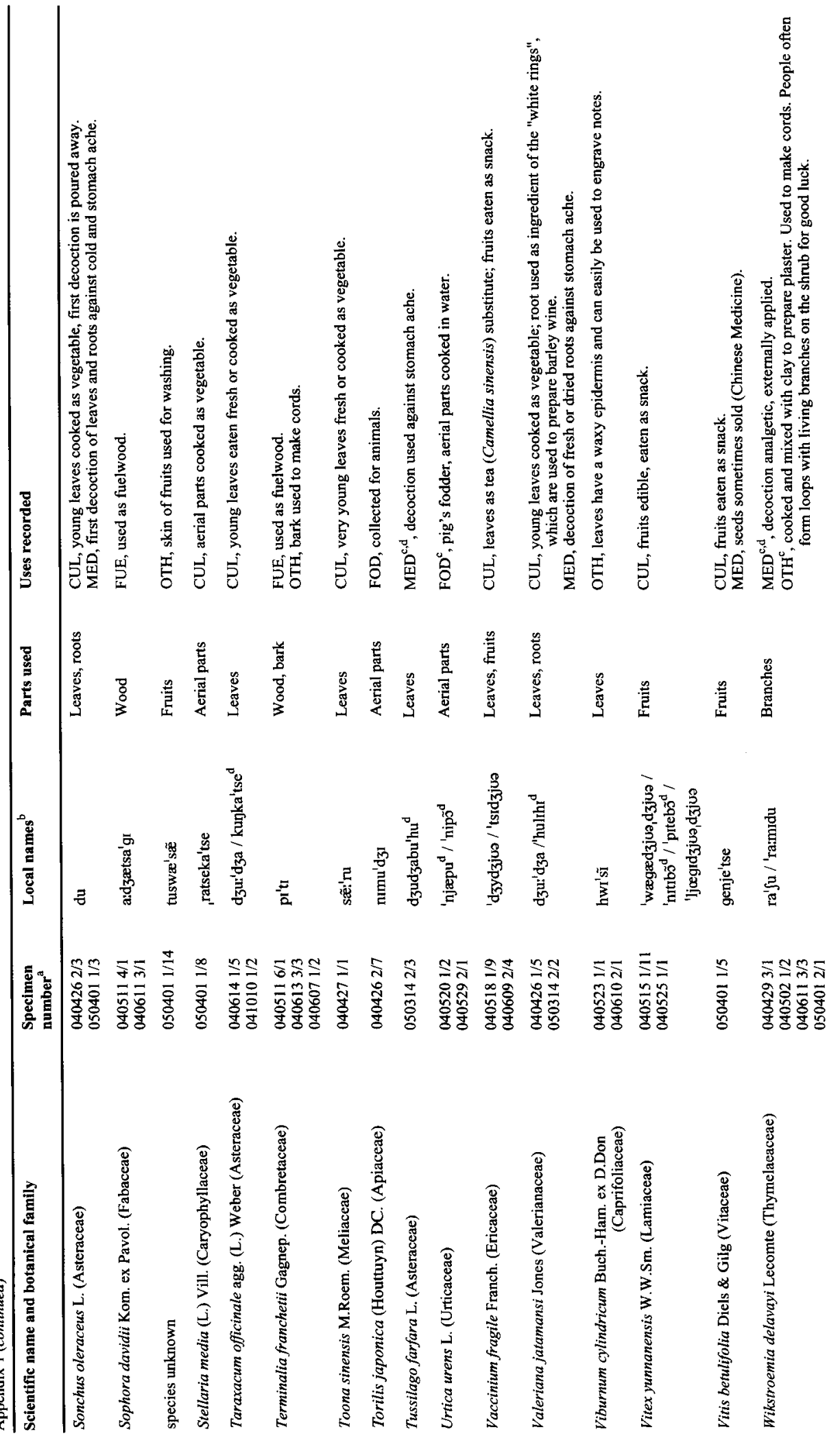




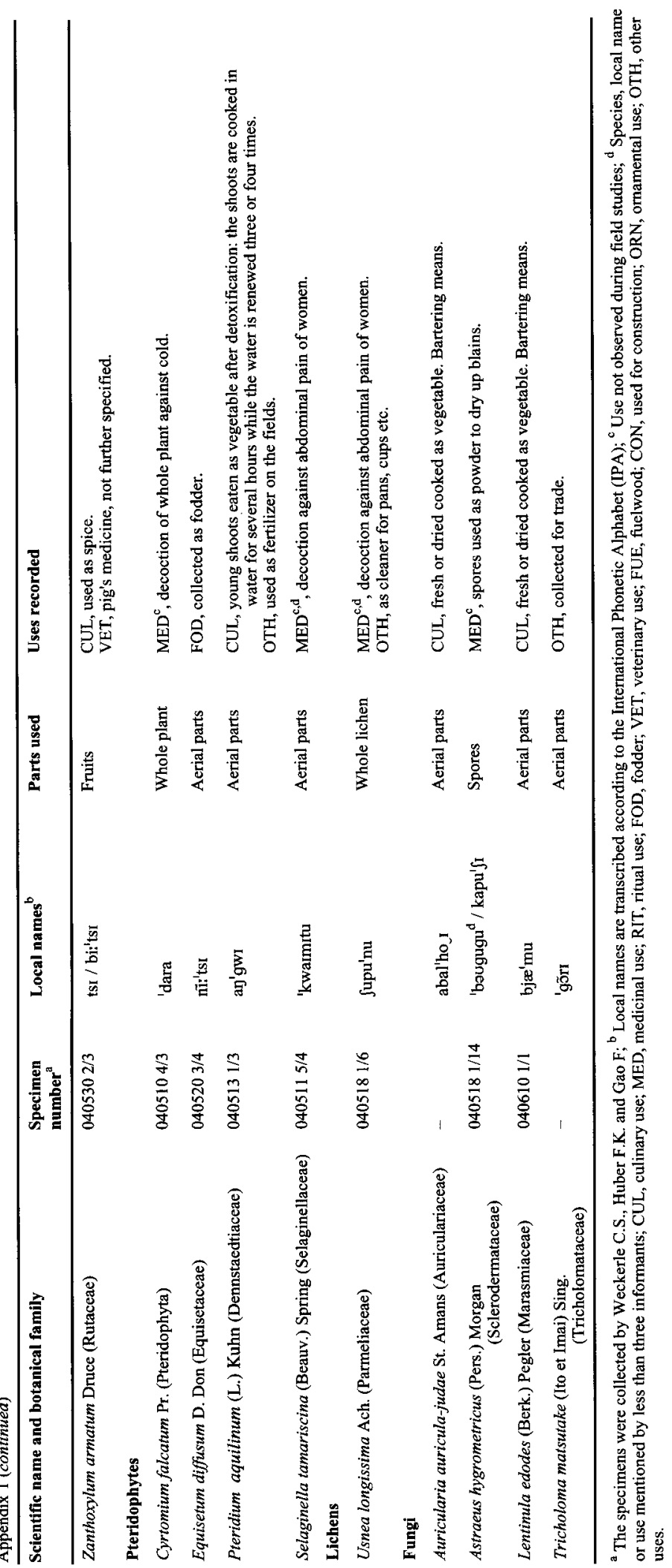

